\title{
New Perspectives on Bulgarian Women of Letters
}

\author{
Review essay by Valentina Mitkova
}

Milena Kirova, ed., Mara Belcheva: Poezia (Mara Belcheva: Poetry), Volume 1, Sofia: Kibea, 2018, 268 pp., BGN 17 (paperback), ISBN 978-954-474-728-2.

Milena Kirova, ed., Mara Belcheva: Proza i prevodi (Mara Belcheva: Prose and translations), Volume 2, Sofia: Kibea, 2018, 350 pp., BGN 19 (paperback), ISBN 978-954-474-729-9.

Vanya Georgieva, Ekaterina Karavelova-Lora Karavelova: Kulturnoistoricheskiat sjuzhet "maiki-dushteri" v bulgarski context (Ekaterina Karavelova-Lora Karavelova: The culturalhistorical subject "mothers-and-daughters" in the Bulgarian context), Sofia: IztokZapad, 2017, 543 pp., BGN 25 (paperback), ISBN 978-619-01-0073-7.

The interest in Bulgarian women writers' lives and intellectual heritage, their individual creative experience and public recognition, falls within the focus of a number of contemporary Bulgarian researchers such as Milena Kirova, Miglena Nikolchina, Amelia Licheva, Nadezhda Alexandrova, Krassimira Daskalova, and Lyudmila Malinova. ${ }^{1}$ Oriented toward the recovery of women authors and intellectuals from the sphere of marginality, where they were traditionally (canonically) positioned, these scholars aim to interpret the creative and public activities of such women as nationally representative and contributing to the formation of modern Bulgarian culture. Drawing critical and public attention to specific cases of women of letters, works such as Mara Belcheva: Poezia (Mara Belcheva: Poetry) and Mara Belcheva: Proza i prevodi (Mara Belcheva: Prose and translations), edited by Milena Kirova, and Ekaterina Karavelova-Lora Karavelova: Kulturnoistoricheskiat sjuzhet "maiki-dushteri" v bulgarski context (Ekaterina Karavelova-Lora Karavelova: The cultural-historical subject "mothers-and-daughters" in the Bulgarian context), by Vanya Georgieva, contribute precisely to the above-mentioned context. Apart from enriching the national literary historiography, they provoke new reflections on prominent places and figures in Bulgarian cultural history.

Mara Belcheva was an early twentieth-century poetess, researcher, and translator of enviable erudition, demonstrating high creative productivity. Nevertheless, Bulgar- 
ian public and critical thought has mainly preserved her image through her biography, individual asceticism, and unusual personal choice to "reflect" the presence of the remarkable male intellectuals who crossed her life-Hristo Belchev, Pencho Slaveikov, Petko Todorov, the German Slavist Georg Adam, Petar Dunov, and others. In cases when the focus fell on the poetic specifics of her work, the dominant interpretive pathos emphasized the influence on her poetry by the distinguished Bulgarian poet, philosopher, and publicist Pencho Slaveikov. Traditionally, the critical view of Belcheva's realization as a woman of letters has occupied the perspective of the exemplary reproduction of Nancy Houston's ${ }^{2}$ thesis on creative couples, where the man took the part of the auctor (author/authority), and the woman the role of the mater (mother/matter), subject to his guidance and modeling.

One hundred years after Mara Belcheva's inauguration in the Bulgarian literary scene, the two-volume critical edition Mara Belcheva: Poezia and Mara Belcheva: Proza i prevodi, initiated and compiled by Milena Kirova, comes to challenge the traditional critical views. It is the first major project covering Belcheva's entire literary heritage and portraying her as an original and significant author. The volumes include her poetry, translations, prose, memoirs, and letters, some of which were unpublished, as well as critical reviews of her works. Richly illustrated with documentary materials and photographs that have remained unknown until now, and accompanied by a psychological portrait, commentary, and detailed notes, the publication stands out with its undisputed contribution to Bulgarian literary history, as well as through its loyalty to the contemporary research agenda to understanding women writers as publicly visible (and significant) subjects.

The first book, Mara Belcheva: Poezia, is comprised of works familiar from the author's three poetry collections: Stupki na praga (Steps on the threshold), 1918; Soneti (Sonnets), 1925; and the auto-anthology Izbrani pesni (Selected songs), 1931. Poems that appeared only on the pages of Bulgarian periodicals are also included, as well as works from the author's archive, unpublished during her life. Belcheva's poetic heritage is presented against its current cultural and historical context, through its critical reception. The latter is represented by the reviews of her poetic books by authors and literary critics such as Dimitar Babev, Vladimir Vasilev, Vasil Pundev, Vladimir Minev, Malcho Nikolov, Boni Gatsov, Petar Dinekov, Georgi Konstantinov, Alexandar Filipov, Ekaterina Kruk-Papazova, Krastina Gicheva-Mihalcheva, and Petar Goryanski.

Setting the coordinates of the overall perception of Mara Belcheva as a person and author and, at the same time, motivating the distance from a simplified perception of her work as imitative and devoid of originality, Milena Kirova's introductory study draws a profound psychological portrait of the poetess. A key motif of the transition the study makes through Belcheva's personal and creative biography is the focus on the conceptual nature of the choice that this talented and highly educated woman made in her early years (and systematically followed to her last days). As explained by the text, it was to stand aside from publicity, at the periphery of literary life; to re-create in a specific way, through existential and artistic self-denial, the modernist pursuit of spiritual individualism, dominating the Bulgarian cultural context of the end of the nineteenth century, "when every writer with the ambition to leave his name in the history of Bulgarian literature played a role in the theater of cultural relations" 
(18). Belcheva's conscious refusal to be a public figure gave her personally the role of the peacemaker, life companion, and spiritual support of the male intellectuals with whom she communicated, throwing light on the introspective nature of her work. That unusual behavioral pattern, called by Milena Kirova, in another text, "the choice to be an echo" ${ }^{3}$ or a need for "plural self-identification," oism, here interpreted through the metaphor "a life in wind silence" (13). What it denotes is the inner, spiritual sustainability of the poetess not only at the stage of her individual and creative formation (the late nineteenth century or the early phase of Bulgarian modernism), but also at different periods of the historical development of the Bulgarian intelligentsia (such as the first decades of the twentieth century). It motivated the way Mara Belcheva was generally recognized by her contemporaries: as a person of another age, belonging to a different moral category; it also largely explains the critical reception of her works.

As evident from the book, Belcheva's poetry was largely accused of lack of identity and personal presence - an interpretative strategy adopted by many of the critical reviews contemporary to her writings. One of the first attempts to "read" her works in modern critical terms - as a nostalgic recollection of the golden age of Bulgarian poetry (passed by the wars and relating the literary subject to the model of Christian heroism) belongs to the literary critic Georgi Konstantinov. What he outlined about the third poetry collection of the poetess titled Izbrani pesni, from 1931-also published in the present volume-was the following: "They remind us of other days, as if a long time ago, when people were more complete and purer, when poetry was about to reveal the person's aspirations and when the person was trying to become poetry" (217).

Mara Belcheva's indisputable talent, her creative sensitivities, her rich erudition and broad cultural interests are demonstrated, in turn, by the second volume edited by Milena Kirova. Dedicated to the author's prose and translations, it contains a number of essays, some of which are published for the first time, such as the essay Zhivotut $v$ golemite gradove (Life in the big cities). Others, like Moite detski spomeni (My children's memories), Pencho Slaveikov: Begli spomeni (Pencho Slaveikov: Blunt memories), Spomeni za Dunov: Svetlia chetvurtak (Memories of Dunov: Good Thursday), and Za velikata chetvorka (On the great four), are already familiar to the audience from earlier editions. Selected by Albena Vacheva and included in the present volume, they "illuminate," once more, the initial stage of Mara Belcheva's personal formation; her fruitful communication with Pencho Slaveikov; cooperation with the literary circle Misal (Thought); and her spiritual involvement in the "White Brotherhood" doctrine, all contributing to the compilation of the author's detailed personal and intellectual portrait. Among the translations listed in the book are the remarkable translation Belcheva did from German of Friedrich Nietzsche's philosophical poem and most popular work, Tui reche Zaratustra (Thus spoke Zarathustra), translated in 1915, and Giacomo Leopardi's poem Poslednata pesen na Sappho (The last song of Sappho), translated in 1921. Her translation of Gerhard Hauptmann's drama in verse Potunalata kambana (The sunken bell) is published for the first time. Found on typography in the National Theater archives and first set on the Bulgarian stage in 1922, the play, rich in romantic and symbolic suggestions, was said to have had an extraordinary influence on early Bulgarian modernism. 
A final touch to the overall image of the poetess, convincingly and deeply depicted by the two-volume edition, is presented by publishing Mara Belcheva's epistolary heritage, prepared by Katia Kuzmova-Zografova. Significant but insufficiently explored, scattered in various archival repositories, it was largely unknown to the Bulgarian audience, except for Belcheva's intense correspondence with Pencho Slaveikov. For the first time in this edition, the author's letters to her contemporaries such as Boni Gatsov, Rayna Yotzova, Svetoslava Slaveikova, her niece Mariana Serafimova-Popitz, Yordan Stubel, and Fani Popova-Mutafova are published. These letters illustrate her states of extreme solitude, her necessity of spiritual empathy, the difficulties in her life, and her creative path. Special attention is paid to the newly studied collection of postcards from Switzerland and Italy, which Mara Belcheva sent to Pencho Slaveikov in 1911, "when the two of them were physically separated but inseparable in their thoughts" (271-272). Selected with an exceptional aesthetic taste by the poetess, containing poems, life and creative commentaries, assumptions for the connections existing among arts, the postcards reflect both the breadth of Mara Belcheva's spiritual world and her personal dedication, the depth of her intellectual and emotional relationship with the prominent Bulgarian poet.

Making a significant contribution to Bulgarian literary historiography, the two-volume edition Mara Belcheva: Poezia and Mara Belcheva: Proza i prevodi is the first systematic attempt to outline the psychological, existential, and creative profile of a remarkable Bulgarian woman writer and intellectual. Remaining true to the high criteria of morality she confessed, as well as to the striving for harmony in life and creativity that she demonstrated, Mara Belcheva undoubtedly belonged (as proved by the volumes) to one of the highest stages in Bulgarian cultural history.

Concentrating on the problematic lives of two other female figures prominent in Bulgarian cultural history-Ekaterina Karavelova and her daughter Lora Karavelova - the work of scholar Vanya Georgieva undertakes, in turn, another pioneering task. After Ralitsa Muharska's volume focused on heredity in Bulgarian feminist writing and the possibility of spiritual mothers and daughters, ${ }^{6}$ Georgieva's study is the first Bulgarian attempt to build a complete scholarly narrative, articulating various aspects (psychological, family, intellectual) of the mother-daughter relationship. Having in mind that the latter have mainly functioned as discursive figures in the conceptual apparatus of contemporary humanitarian studies, the text makes an innovative attempt to "escape" from dominant metaphors and mythological stories. Instead, it chooses to comment on a particular mother and daughter's personifications (Ekaterina and Lora Karavelova), following their real historical paths as women writers and active participants in the public life of modern Bulgaria at the beginning of the twentieth century. The task to outline women's experiences in a specific cultural and historical context, as well as to show the tensions typical of the mother-daughter relationship, is achieved by this study through reference to primary, documentary sources. The result is a detailed analysis but also a fascinating narrative. Finally, the text demonstrates the productivity of "biographical reconstruction as a cultural and literary tool," proving "the necessity of the persistent philological attention to the memoir, always revealing another, different view of the whole cultural life in a certain space-and-time period, and to the curious micro stories in its foundations" (7). 
The first two chapters of the work, "Konstruktivnata metafora 'maiki-dushteri': Mehanizmi na chetene" (The constructive metaphor "mothers-and-daughters": Reading mechanisms) and "Maiki i dushteri: Sobstven diskurs-sobstvenost na diskursa" (Mothers and daughters: Their own discourse-property of the discourse), outline the scientific parameters in which Vanya Georgieva's study locates its interests and builds its own research optics. Its intention to offer a new perspective on a particular Bulgarian version of the popular cultural and historical narrative about mothers and daughters is aimed, first, at decoding the complex (both creative and destructive) aspects of the relationships between women linked in a biological alliance. Second, the text is an attempt to illuminate a specific female experience (intellectual, social, and political) in the public sphere of the country. Its third ambition is to formulate a different view of popular phenomena and processes in Bulgarian cultural history. The text proceeds to the accomplishment of its intentions by first focusing on the postulates of the mid-1970s psychoanalytic feminist theory as one of the most influential interpretive matrices of the complex mother-daughter relationship). The possibility of defending the female tradition through authority, the formula of "heredity," the opportunity to reproduce a particular paradigm of experience, beyond the patriarchal (power) model, where "the women's voice" is utterly authentic, are subjected to a close reading by Vanya Georgieva's study, later to be analyzed as unrealized scenarios in Ekaterina and Lora Karavelovi's case.

Apart from Western feminist theory and criticism sensitive to mother-daughter relations, the text also concentrates on the contemporary Bulgarian studies of the history of women intellectuals and public figures. Entwined in a large humanitarian tradition, the latter, resulting in an impressive array of critical texts, articulate the local experience of focusing on women's movements in Bulgaria, women authors' problematic lives and hindered public visibility, and women's representations, among other themes. Bulgarian feminist writing (following the experience of Western feminist thought from the 1970s to the 1990s) has demonstrated, according to Georgieva, sharp sensitivity to the missing tradition of the female creative presence, the "matriarch question," the origin of women's intellectual (nonbiological) genealogy. Hence, the logical question posed by Vanya Georgieva's study: Do writing women, generally hardly admitted as individuals to the record of the national literary history, have more chances to be canonically recognized if presented as belonging to a "literary generation," as a part of collective identities?

The emphasis on inheritance practices, the focus on the dialogue between women's generations, personified by mothers and daughters, is crucial to the book under review here, resolved into real cases - the biographies of a specific mother and daughter. The interaction between the existing methodological tradition and the specificity of the author's quests is sought through activation of other-besides feminist-disciplinary fields such as sociology, cultural studies, psychology, psychoanalysis, and literary studies. Their commitment to peripheral areas, local events, and minor stories, "working" within the scientific regimes of postmodernism and new historicism, is viewed as productive to gaining better understanding the particular mother-daughter story.

Precisely such research reflections on the subject that go beyond the big, generalizing narratives are deployed in the second part of Vanya Georgieva's study. Com- 
prised of chapters titled "Maiki i dushteri-otnoshenieto mezhdu trima" (Mothers and daughters - the relationship among three); "Dushteriata Ekaterina Karavelova: Maikata Ekaterina Karavelova" (The daughter Ekaterina Karavelova: The mother Ekaterina Karavelova); “Lora Karavelova: Spraviane s 'Lora Karavelova'” (Lora Karavelova: Dealing with 'Lora Karavelova'); "Purvite ot svoia vid" (The first of their kind); and "Povtorenie i subitie" (Repetition and event), it performs a detailed biographical reconstruction of the complicated mother-daughter relationship of Ekaterina Karavelova and Lora Karavelova. Priority is given to the memoir and epistolary genres, modes of writing implying a maximum degree of authenticity in (self-)image building, auto-reflexivity to personal stories, able to reveal certain processes and psychological twists in the heroines' biographies, which have remained unknown in their public versions. A careful revision of the latter is done by this study through analyzing various aspects of Ekaterina's and Lora's childhood and early years, which marked their personal formation. These stages are interpreted as predetermining certain behavioral patterns and choices in life, with which the two women identified themselves.

Ekaterina Karavelova was mainly remembered by her contemporaries (and Bulgarian cultural history too) for her political and social engagement, as well as for her marriage to the prominent Bulgarian politician and public activist Petko Karavelov. When analyzing her biography, however, the text seeks and finds those episodes in her life that formed her conservatism and authoritarianism as a parent, her inability to accept her children's unconventional choices. According to the study, it was the striving to project her own ambitions on her daughters that largely determined the ruinous consequences for Lora Karavelova. The dramatic mother-daughter scenario that evolved over time proves the author's questioning, after Élisabeth Badinter, ${ }^{7}$ whether maternal love is an exclusively natural instinct or a tendency reinforced in the cultural context, where the behavior of motherly affection is expected.

The problematic nature of the latter, shown in the specificity of the case analyzed by Vanya Georgieva, is the key to a possible (different) reading of Lora's end "not only through the extreme character of the hetero-erotic love-in-death, but as an epilogue of a particular family relationship, to which the young woman directed enormous energy throughout her life-the relationship with her mother" (479). Following such an interpretative line, the text is hesitant about Lora Karavelova's popular public reception as a "femme fatale" (fatal woman), obsessed with her exuberant feelings for her husband, the poet Peyo K. Yavorov. On the contrary, the study tends to think of her as a victim of her environment and her loved ones, who tried to push her in "forcibly set directions, deliberately constructed worlds" (479).

In the context of the mother-daughter relationship and using the methods of sociology and psychoanalysis, the study also offers a nontraditional interpretation of Yavorov himself. In his attitude toward Lora, the poet is shown to be a person close in character to her mother: both of them favored a good public image at the expense of the personal life threatening to domesticate them; both were not fully committed in their love to Lora, provoking her anger and misunderstanding (169).

In Vanya Georgieva's interpretation, the mother-daughter conflict is also influenced by the fact that Ekaterina Karavelova and Lora Karavelova, both intellectuals and women of letters, did not associate, in terms of their creativity, in a "hereditary 
line." Although the works of the two refused to follow the normative concepts of women's writing, to "speak" in the register of the "natural" female emotionality, Ekaterina Karavelova and Lora Karavelova followed different creative paths. The mother, driven by her enlightenment dream of the inclusion of women in the social and cultural life of modern Bulgaria, created political feuilletons, literary criticism, translations; the daughter was a short prose author, writing "mostly to express the non-acceptance of her mother" (479).

By demonstrating an impressive depth of research, and an ability to utilize different methodologies and question already available arrays of knowledge as well as wellestablished directions of interpretation, Vanya Georgieva's book is truly successful in its intention to offer a thorough analysis of the mother-daughter relationship through its real historical representation. Applied to the story of Ekaterina Karavelova and Lora Karavelova, the subject is portrayed in all its complexity, beyond the popular (and already articulated) versions of the tensions that existed between the two women intellectuals.

Telling their heroines' dramatic paths of personal and creative self-determination, focusing on the contradictory public and private (family) resonances of the life choices they made, opposing patriarchal mentalities (surprisingly persistent in the context of modern Bulgaria at the time), praising their productivity and erudition, the works by Vanya Georgieva and Milena Kirova both succeed in bringing women writers back into the light of public and scholarly interest, as well as on to the stage of the cultural and historical narrative.

\section{$\diamond$ About the Author}

Valentina Mitkova received her PhD in book history from Sofia University St. Kliment Ohridski and is currently an Assistant Professor at the same university. She is an author of several book reviews and critical materials for Aspasia, as well as of articles for Bulgarian periodicals focused on Bulgarian women writers and intellectuals (18781944). E-mail: valentina.mitkova@abv.bg

\section{$\diamond$ Notes}

1. Milena Kirova, Neslucheniat kanon: Bulgarskite pistelki ot Vuzrazhdaneto do Vtorata svetovna voina [The canon that did not happen: Bulgarian women writers from the Revival to World War II] (Sofia: IK Altera, 2009); Milena Kirova, Neslucheniat kanon: Bulgarskite pistelki ot 1944 godina do nashi dni [The canon that did not happen: Bulgarian women writers from 1944 to today] (Sofia: IK Altera, 2013); Krassimira Daskalova, "Zhenska identichnost: Normi, predstavi i obrazi v bulgarskata kultura ot XIX-nachaloto na XX vek" [Female identities: Norms, ideas, images in the Bulgarian culture from XIX to the beginning of XX century], in Balkanski identichnosti [Balkan identities] (Sofia: UI Sv. Kliment Ohridski, 2001), 182; Krassimira Daskalova, "Zhenite i bulgarskata knizhnina (1878-1944)" [Women and Bulgarian literature (1878-1944)], in Godishnik na Sofiyskia universitet Sv. Kliment Ohridski: Centar po kulturoznanie [Yearbook of Sofia University St. Kliment Ohridski: Center for Cultural Studies]), vol. 86 (Sofia: UI Sv. Kliment Ohridski, 1993); Krassimira Daskalova, "Bulgarskite zheni v socialni dvizhenia, zakoni i diskursi (1840-1940)" [Bulgarian women in social movements, laws, and discourses (1840-1940)], in Ot 
siankata na istoriata: Zhenite $v$ bulgarskoto obshtestvo i kultura (1840-1940) [From the shadows of history: Women in Bulgarian society and culture (1840-1940)] (Sofia: IK Dom na naukite za choveka i obshtestvoto, 1998); Krassimira Daskalova, Zheni, pol i modernizacia v Bulgaria, 1878-1944 [Women, gender, and modernization in Bulgaria, 1878-1944] (Sofia: UI Sv. Kliment Ohridski, 2012); Miglena Nikolchina, Rodena ot glavata: Fabuli i sjuzheti v zhenskata literaturna istoria [Born from the head: Fables and stories in women's literary history] (Sofia: IK Sema RSH, 2002); and Lyudmila Malinova, Bulgarskite poetesi mezhdu dvete svetovni voini [Bulgarian poetesses during the interwar period] (Sofia: IK Vanyo Nedkov, 1999).

2. Nancy Huston, Journal de la creation [Diary of creation] (Paris: Seuil, 1990).

3. Milena Kirova, Mara Belcheva, ili izborat da budesh Eho (Mara Belcheva or the choice to be Echo) http://www.public-republic.com/magazine/2010/08/56503.php (accessed 20 December 2018).

4. Ibid.

5. The (Universal) White Brotherhood is a religion-philosophical doctrine, also called Dunovism, which was established in Bulgaria in 1897. Its founder and ideologist was the philosopher Petar Dunov, called "The Master" or Beinsa Duno by his followers. Defined as esoteric Christianity and occultism, the White Brotherhood proclaimed love, wisdom, truth, justice, and virtue as its major categories, perceived as attributes of the "historical, cosmic and mystical Christ." The various ideological aspects of the doctrine were developed in about four thousand sermons of Dunov, articulated and stenographed between 1914 and 1944, later published in several multivolume series. Basic methods for studying Dunov's works and commemorating his ideas used at the School of the White Brotherhood (which has its contemporary followers too) are: spiritual meetings, musical exercises, reading of Dunov's texts, meeting the sunrise, mountain excursions, living in fraternal communities, and so forth.

6. Ralitsa Muharska, Maiki i dushteri: Pokolenia i posoki v bulgarskia feminizum [Mothers and daughters: Generations and directions in Bulgarian feminism] (Sofia: Polis, 1999).

7. Élisabeth Badinter, L'amour en plus: Histoire de l'amour maternel (XVIIe-XXe siècle) [Extra love: History of maternal love (17th-20th century)] (Paris: Flammarion, 1980). 